\title{
Comparison of recovery time of ketamine versus nalbuphine used in combination with propofol in females undergoing in- vitro fertilization under intravenous sedation.
}

1. MBBS, FCPS

Assistant Professor Anesthesia

Ameer ud Din Medical College /

LGH Lahore.

2. MBBS, FCPS

Associate Professor Anesthesia Services Institute of Medical Sciences,

Services Hospital Lahore

3. MBBS, FCPS

Consultant Anesthetist Kaul Associates, Lahore.

4. MBBS, FCPS

Senior Consultant Anesthetist Kaul Associates, Lahore.

5. MBBS, FCPS

Assistant Professor Anesthesia Avicenna Medical College, Lahore.

6. MBBS, FCPS

Assistant Professor Anesthesia Faisalabad Medical University/ Allied Hospital, Faisalabad.

\section{Correspondence Address:}

Dr. Mohsin Riaz Askri

Assistant Professor Anesthesia

Faisalabad Medical University/

Allied Hospital, Faisalabad.

mohsinriaz46@yahoo.com

Article received on:

08/05/2020

Accepted for publication: 20/08/2020

\section{INTRODUCTION}

Day care surgery has become immensely popular throughout the world. The major advantage of the day care surgery is cost effectiveness, early discharge and less stress to the patient. Early recovery time from anesthesia is the main goal in day care surgeries. ${ }^{1}$ There are many methods of anesthesia for patients undergoing day care surgeries like general anesthesia with inhalations or intravenous sedation, regional anesthesia or total intravenous sedation with analgesia. The ideal anesthetic technique for a day care surgery should provide good surgical anesthesia with minimum stress, a short recovery time, shortest duration of exposure and maximum comfort to patient along with less postoperative side effects. ${ }^{2,3}$ In-vitro fertilization is one of the procedure done as a day care surgery. Women coming for in-vitro fertilization are extremely anxious and under great stress. They also experience mild to moderate pain by the puncture of the ovarian capsule in order to take the oocytes, so anesthesiologists are increasingly being challenged by the peculiar nature of this procedure. ${ }^{4} \mathrm{~A}$ favorable analgesic regimen for oocyte retrieval must have no toxic effects on the oocytes with rapid onset, rapid recovery, ease of administration, and monitoring. ${ }^{2,4}$

Different methods of conscious sedation and analgesia have been used for oocytes recovery for IVF techniques. ${ }^{4}$ Propofol, the most commonly used sedating agent, is suitable for day care IVF procedures as its a potent hypnotic agent with rapid onset of action and rapid recovery. ${ }^{5}$ But it is inadequate as sole agent as it lacks analgesic properties and so used with different agents. ${ }^{6,7}$ While opioid analgesics can be used as the solitary supplement they do not provide reliable sedation without considerable respiratory depression. ${ }^{8}$ Practicing combination of two agents increases 
safety and efficacy, provides better patient control and allows the use of smaller doses of each single agent avoiding its undesirable effect ${ }^{9,10}$ Therefore opioids are most commonly used in conjunction with sedative drugs. ${ }^{8}$

Nalbuphine hydrochloride is a synthetic opioid agonist-antagonist. It is a potent analgesic that can be used as a supplement with propofol for balanced anesthesia, and for preoperative and postoperative analgesia. ${ }^{11}$ It acts as a partial agonist at kappa receptors and an antagonist at $\mu$ receptors. It has minimal side effects, and exhibits a ceiling effect for respiratory depression. ${ }^{12,13}$

Ketamine, an NMDA receptor antagonist is increasingly used for short term painful procedures in doses of 0.1-0.6 mg/kg. ${ }^{10}$ Currently, ketamine and propofol are used in the ED as a sedative drug in short procedures. ${ }^{14}$ The untoward effects of ketamine and propofol are reduced and balanced by each other as a combination producing synergistic, smoother sedation. ${ }^{7}$ Ketamine in combinations with propofol provide analgesic effect, shorter recovery time with decreased incidence of vomiting. ${ }^{10,15}$ Various combinations with propofol have been studied earlier but none has been done to compare propofol-ketamine with propofol-nalbuphine. Thus, the objective of this study was to compare the mean recovery time after administration of propofol-ketamine versus propofol-nalbuphine combination in patients undergoing in-vitro fertilization procedures under intravenous sedation.

\section{MATERIAL \& METHODS}

After approval from Ethical Review Committee, 60 patients of ASA I and ASA 2 were selected using random number tables and patients were divided into two groups, A and B undergoing elective in-vitro fertilization procedures. An informed consent was taken from each patient, the relevant investigations were done after taking a detailed history and patients were kept nil per orally for 6 hours before procedure. All the patients were given inj. midazolam $0.03 \mathrm{mg} / \mathrm{kg} \mathrm{I} / \mathrm{V} 10 \mathrm{~min}$ before induction. Group A received a fixed dose of inj. nalbuphine $0.06 \mathrm{mg} / \mathrm{kg}$ along with inj. propofol with $20 \mathrm{mg}$ initial bolus and later $10 \mathrm{mg}$ for supplemental drug doses as required to maintain deep sedation. Group B received a fixed dose of inj. ketamine $0.3 \mathrm{mg} / \mathrm{kg}$ along with inj. propofol with $20 \mathrm{mg}$ initial boluses and $10 \mathrm{mg}$ for later supplemental drug doses as required to maintain deep sedation. All patients were maintained on spontaneous ventilation using face mask. In cases of apnea, patients were manually ventilated till spontaneous ventilation was maintained. The recovery time was calculated from discontinuation of propofol till the eye opening of the patients on verbal command.

Statistical analysis was done using statistical package for social sciences (SPSS) version 24.

Quantitative data i.e. age, weight, recovery time were presented as mean and standard deviation. The two groups were compared by independent sample $t$ test for recovery time, taking $p$ - value equal or less than 0.05 as significant.

\section{RESULTS}

In this study there were total 60 cases, 30 in each group included. The mean age in group A was 27.53 \pm 3.36 years while in group $B$ was $26.33 \pm 2.44$ years (Table-I). The mean weight in group A was $63.45 \pm 3.21$ years while in group B was $62.78 \pm 5.23$ years as in Table-l. Recovery time was significantly better in group A (Nalbuphine) where it was seen as $4.73 \pm 0.98$ minutes as compared to $7.17 \pm 1.14$ minutes in group B with $p=0.01$ as in Table-Il. Recovery time was better in younger age groups (20-27 years) in Nalbuphine group (4.43 \pm 0.91 minutes with $p=$ 0.01 ) (Table-III). Patients weighing $50-59 \mathrm{~kg}$ and $60-70 \mathrm{~kg}$ showed faster recovery time in group A as compared to group B. (Table-IV).

\begin{tabular}{|c|c|c|c|c|}
\hline & \multicolumn{2}{|c|}{ Group A } & \multicolumn{2}{|c|}{ Group B } \\
\hline Age & \multicolumn{2}{|c|}{$27.53 \pm 3.36$} & \multicolumn{2}{|c|}{$26.33 \pm .44$} \\
\hline Weight & \multicolumn{2}{|c|}{$63.45 \pm 3.21$} & \multicolumn{2}{|c|}{$62.78 \pm 5.23$} \\
\hline \multicolumn{5}{|c|}{ Table-I } \\
\hline & Group A & \multicolumn{2}{|c|}{ Group B } & P-Value \\
\hline $\begin{array}{l}\text { Recovery Time } \\
\text { (minutes) }\end{array}$ & $4.73 \pm 0.98$ & \multicolumn{2}{|c|}{$7.17 \pm 1.14$} & 0.01 \\
\hline \multicolumn{5}{|c|}{ Table-II } \\
\hline
\end{tabular}




\begin{tabular}{|l|c|c|c|}
\hline \multicolumn{4}{|c|}{ Recovery Time (minutes) } \\
\hline Age (years) & Group A & Group B & p-value \\
\hline $20-27$ & $4.43 \pm 0.91$ & $7.01 \pm 1.09$ & 0.01 \\
\hline $28-35$ & $4.76 \pm 0.99$ & $7.53 \pm 1.19$ & 0.01 \\
\hline \multicolumn{4}{|c|}{ Table-III } \\
\hline \multicolumn{4}{|c|}{ Recovery Time (minutes) } \\
\hline Weight (kg) & Group A & Group B & p-value \\
\hline $50-59$ & $4.52 \pm 0.93$ & $7.10 \pm 1.11$ & 0.01 \\
\hline $60-70$ & $4.98 \pm 1.01$ & $7.92 \pm 1.19$ & 0.01 \\
\hline
\end{tabular}

\section{DISCUSSION}

One of the most recent advances in the treatment of infertility is In vitro fertilization (IVF). For improved patient outcome, it has undergone various advances. ${ }^{16}$ The use of this technology is increasing day by day. These procedures are being performed as a day case procedure. Previously performed laproscopically, the oocyte retrieval is now performed through vagina which is much less invasive. ${ }^{17}$ This process required analgesia with or without sedation because it is very painful and stressful one. ${ }^{16,18}$ Different studies has used different anesthetic modalities and analgesic regimen but no definite conclusion so far been made regarding the preferred anesthetic and analgesic regimens for these procedures. ${ }^{19}$

Due to lower incidence of respiratory tract complications and advantages of verbal communications with the patient, regional methods with conscious sedation are preferred one. General anesthesia with sedation and analgesia has been found to be the superior method due to advantages of facilitating ovarian aspiration, reducing uterine tone, removing anxiety and preventing patient movements. ${ }^{20,21}$

Deep level of sedation is obtained by adding small dose of propofol while ketamine gives good analgesia in small dose with minimal sedation. ${ }^{22}$ This combination of ketamine and propofol provides good sympathomimetic stability. Ketofol as combination of $50 \%$ propofol and $50 \%$ ketamine $(5 \mathrm{mg} / \mathrm{ml}$ of each) is widely used for procedural sedation and analgesia with high level of effectiveness and satisfaction. ${ }^{22}$ Opiod with propofol is also an effective combination. Propofol and fentanyl has been used in many studies but we used nalbuphine with propofol. Literature regarding use of these combinations in IVF is still deficient.

Recovery time in our study was significantly shorter in group $A$ treated with nalbuphine $(4.73 \pm 0.98$ $\mathrm{min})$ vs $(7.17 \pm 1.14 \mathrm{~min})$ in group $B$ treated with ketamine (both in conjunction with propofol) ( $p$ value $=0.01$ ). When recovery time was compared in terms of age and weight, it was significantly decreased in Group A than group B. $(p=0.01)$ There was no such one to one comparison of these two agents especially in cases with in vitro fertilization.

The results of a study by Mora-Gonzalez et al reported shorter time of recovery with propofol-- nalbuphine $(11.3 \pm 4.3 \mathrm{~min})$ than dexmedetomedine-fentanyl which was consistent to our study results. ${ }^{23}$

In the study by Urfalioglu et al, the recovery time was statistically significantly shorter in propofolremifentanil group in comparison to propofolketamine. $(p<0.001)$ This was comparable to our study results where we also found propofolnalbuphine better than propofol-ketamine combination. The difference was the type of opioid used and the time of recovery was determined as median. 6 mins (range, 3-9 mins) for Group P than that for Group PK of 7 mins (range, 5-10). ${ }^{20}$

Studies done earlier show contrasting results which may be attributed to variation in dose and interpretation. In a study of Dexmedetomidine versus Ketofol Sedation for Outpatient Diagnostic Transesophageal Echocardiography by Sruthi et al, the recovery time was comparable among the two groups which was approximately $2.6 \mathrm{~min}$ expressed as median. This was not consistent with our results as we reported the time in mean $\pm s d .^{7}$

Ejaimi et al evaluated Ketamine/Propofol Combination for Deep Sedation and Analgesia in Minor Painful Operations and observed the time from the last dose to full recovery to range from 10 
- 20 min. (mean: 15 minutes.) This was different from our results where the mean recovery time was $7.17 \mathrm{~min}$. This could be due to difference in doses of ketamine and propofol. They used 5mg/ $\mathrm{ml}$ of each agent in combination whereas we used separately $0.3 \mathrm{mg} / \mathrm{kg}$ ketamine and $10 \mathrm{mg}$ initial bolus with $10 \mathrm{mg}$ supplemental propofol. ${ }^{22}$

A study by Tajoddini et al revealed shorter recovery time (5.65 $\pm 0.35 \mathrm{~min})$ with propofol- ketamine when compared to propofol-fentanyl for sedation and analgesia in emergency procedures. This difference in results could be due to different methodology. ${ }^{15}$

Panjabi et al did not find significant difference in the recovery time when comparing nalbuphine and fentanyl for post-operative pain relief in patient undergoing short surgical procedures. $(8.8 \pm 1.0$ minutes vs $7.8 \pm 1.5 \mathrm{~min}) .{ }^{24} \mathrm{In}$ another study by Madacsy et al no difference was seen in recovery time when propofol-nalbuphine was compared with propofol alone for deep sedation for colonoscopy (51.7 $\mathrm{min} \pm 23.4$ vs. $49.5 \mathrm{~min} \pm$ 21.7, $\mathrm{p}=0.4){ }^{25}$

There were few limitations of the study. As this study did not look for the other parameters like pain relief, sedation scores and side effect profiles of the drugs used in both groups. Future studies need to be designed to investigate the effects of these drugs. In conclusion, our findings reveal that propofol-nalbuphine provides faster recovery time as compared to propofol-ketamine combination.

Copyright@ 20 Aug, 2020.

\section{REFERENCES}

1. Bajwa SJ, Sharma V, Sharma R, Singh AP. Anesthesia for day-care surgeries: Current perspectives. Med J DY Patil Univ 2017; 10:327-33.

2. Matsota P, Kaminioti E, and Kostopanagiotou G. Anesthesia related toxic effects on in vitro fertilization outcome: Burden of proof. Biomed research international. 2015:1-9.

3. Shagufta Choudhary*, M.M. Begani**, Dheeraj Mulchandani Choice of anaesthesia for day care surgery. Bombay Hospital Journal, 2015; 57(2):173177.
4. Sharma A, Borle A, Trikha A. Anesthesia for in vitro fertilization. J Obstet Anaesth Crit Care 2015; 5:62-72.

5. Elzohry AA1* , Adnan Ahmed Ali2, Waleed Attia Hassan2 and Wael Abd Elgwad Elsewify Dexmedetomidine as a Sole Sedative Agent versus Propofol for Sedation during Upper and Lower Gastrointestinal Endoscopies. Dev Anesthetics Pain Manag 2018; 1(4):1-8.

6. Nazemroaya B, Majedi MA, Shetabi H, Salmani S. Comparison of propofol and ketamine combination (Ketofol) and Propofol and Fentanyl Combination (Fenofol) on Quality of Sedation and Analgesia in the Lumpectomy: A Randomized Clinical Trial. Adv Biomed Res 2018; 7:134.

7. SruthiS, MandalB, RohitMK, PuriGD. Dexmedetomidine versus ketofol sedation for outpatient Diagnostic transesophageal echocardiography: A randomized controlled study. Ann Card Anaesth 2018; 21:143-50.

8. Elsersi MH, Abuelghar WM, Makled AK. The emergence profile of propofol sedation compared with dexmedetomidine injection during ultrasoundguided oocyte pickup for in-vitro fertilization AinShams J Anesthesiol 2015; 08:327-333.

9. Nallam SR, Chiruvella S, Reddy A. Monitored anaesthesia care - Comparison of nalbuphine/ dexmedetomidine versus nalbuphine/propofol for middle ear surgeries: A double-blind randomised trial. Indian J Anaesth 2017; 61:61-7.

10. Salem HA Low-Dose Ketamine and propofol combination for upper endoscopy in morbidly obese patients. Glob J Anesth 2017; 4(1): 006-012.

11. Mohammed KS, Ali KE, Ahmed HE, Ibrahem HA. Comparative study between midazolam versus nalbuphine on prevention of emergence agitation after sevoflurane anesthesia in pediatric patients undergoing tonsillectomy with or without adenoidectomy. Tanta Med J 2017; 45:73-8.

12. Zhao N, Wu Y, Yu C. Effect of intravenous nalbuphine on emergence agitation in children undergoing dental surgery under sevoflurane anesthesia. Int $\mathrm{J}$ Clin Exp Med 2018; 11(9):10215-10222.

13. Deng $C$, Wang $X$, Zhu $Q$, Kang $Y$, Yang J, Wang $H$ (2017) Comparison of nalbuphine and sufentanil for colonoscopy: A randomized controlled trial. PLoS ONE 12(12):e0188901.

14. Ghojazadeh M, Sanaie S, Paknezhad SP, Faghih SS, Soleimanpour $\mathrm{H}$. Using ketamine and propofol for procedural sedation of adults in the emergency department: A systematic review. and MetaAnalysisAdv Pharm Bull 2019; 9(1): 5-11. 
15. Tajoddini, S., \& Motaghi, M. Sedative and analgesic effects of propofol-ketamine versus propofolfentanyl for emergency department procedures. Hong Kong Journal of Emergency Medicine 2020;1-8.

16. Vasudevan B, Borle A, Singh PM, Ramachandran R, Rewari V, Trikha $A$. The effect of anesthetic technique for transvaginal ultrasound-guided oocyte retrieval on reproductive outcomes: A systematic review and meta-analysis. J Obstet Anaesth Crit Care 2015; 5:5461.

17. Kwan I, Bhattacharya S, Knox F, McNeil A. Pain relief for women undergoing oocyte retrieval for assisted reproduction. Cochrane Database Syst Rev 2013; 1:CD004829.

18. Vlahos NF, Giannakikou I, Vlachos A, Vitoratos N. Analgesia and anesthesia for assisted reproductive technologies. Int J Gynaecol Obstet 2009; 105:201-5.

19. Sharma A, Borle A, Trikha A. Anesthesia for in vitro fertilization. J Obstet Anaesth Crit Care 2015; 5(2):6272.

20. Urfalioğlu A, Yaylalı. Effect of anesthetics during oocyte pick-up procedure on oocyte quality and pregnancy. J Clin Anal Med 2016; 7(6): 840-3.
21. Edwards JA, Kinsella J, Shaw A, Evans S, Anderson KJ. Sedation for oocyte retrieval using target controlled infusion of propofol and incremental alfentanil delivered by non-anaesthetists. Anaesthesia 2010; 65(5):453-61.

22. Ejaimi G, Salama A. A prospective evaluation of "Ketofol"(Ketamine/Propofol Combination) for deep sedation and analgesia in minor painful operations. Annual of International Medical and Dental Research. 2016; 2(2): 46-53.

23. De la Mora-González JF, Robles-Cervantes JA, MoraMartínez JM, Barba-Alvarez F, Llontop-Pisfil EC, González-Ortiz M, Martínez-Abundis E, Llamas-Moreno JF and Bermúdez MCE. Hemodynamic effects of dexmedetomidine-fentanyl vs. nalbuphinepropofol in plastic surgery M.E.J. Anesth 2012; 21 (4):553-57.

24. Panjabi GM, Tank PR. A comparative study of Nalbuphine and fentanyl for post operative pain relief in patients undergoing short surgical procedures. IOSR J Dental Med Sci. 2015; 14(10):15-18.

25. Madácsy L, Gellért B, Murányi M, Lippai D, Tulassay $Z$. Safety and effectiveness of anesthesiologistadministered Propofol versus Propofol and Nalbuphine for deep sedation during and after outpatient colonoscopy. Z Gastroenterol 2015; 53 A34.

\begin{tabular}{|c|l|l|l|}
\hline \multicolumn{3}{|c|}{ AUTHORSHIP AND CONTRIBUTION DECLARATION } \\
\hline Sr. \# & \multicolumn{1}{|c|}{ Author(s) Full Name } & \multicolumn{1}{|c|}{ Contribution to the paper } \\
\hline 1 & Muazzam Butt & $\begin{array}{l}\text { Study design, Concept, Data } \\
\text { analysis. } \\
\text { Questionaire, Design, Main } \\
\text { script writing. } \\
\text { Data collections, Data analysis. }\end{array}$ \\
\hline 2 & Saadia Khalique & Hamza Waheed & $\begin{array}{l}\text { Manuscript review, Literature \& } \\
\text { review. } \\
\text { Methodology, Proof reading. }\end{array}$ \\
\hline 5 & Shamila Athar & Zulqarnain Butt & Supervision, Methodology, \\
\hline 6 & Mohsin Riaz Askri & Proof reading. \\
\hline
\end{tabular}

